\title{
Herramientas para el pensamiento
}

Tools of thinking

\author{
Eduardo Vázquez-Domínguez ${ }^{a}$, María del P. Gómez Ortiz ${ }^{b}$
}

\begin{abstract}
:
In this globalized world, the search for new consumers is a priority, so that every company is asking its designers to develop products or services that connect in a better way with the wishes and needs of its consumers, that is why every professional that has contact with the industry or the services must know tools which point to the innovation, which develop the use of the thought of design of effective way for the prototypes.

The different tools of thought presented here tend to develop a very different vision of how to innovate, as if at the time the tendency was to innovate to solve a need or create a new need or desire in consumers, at this time that is no longer enough, now we are looking to develop products or service that are connected to the needs, senses and feelings of consumers and for this the designer mu st know: what does he/she want?, what does she/he feel? and how to build unique experiences in the client and how knowing this allows it to anticipate future needs, which not only solve the client's needs in the best way, but also cause a high degree of satisfaction, which will lead the customer to a loyalty to the brand.
\end{abstract}

\section{Keywords:}

Creativity, ideas, products, customers

\section{Resumen:}

En este mundo tan globalizado, la búsqueda de nuevos consumidores es prioritario, de tal forma que toda empresa está pidiend o a sus diseñadores que desarrollen productos o servicios que conecte de mejor manera con los deseos y necesidades de sus consumidores, es por ello que todo profesionista que tenga contacto con la industria o los servicios debe conocer herramientas que apunten a la innovación, las cuales desarrollan el uso del pensamiento de diseño de manera efectiva para el desarrollo de prototipos.

Las distintas herramientas del pensamiento aquí presentadas tienden a desarrollar una visión muy distinta de como innovar, ya que si en su momento la tendencia fue innovar para resolver una necesidad o crear una nueva necesidad o deseo en los consumidores, en estos tiempos eso ya no es suficiente, ahora se busca desarrollar productos o servicio que estén conectados con las necesidad es, sentidos y sentimientos de los consumidores y para ello el diseñador debe de saber: ¿qué quiere?, ¿qué siente? y como construir experiencias únicas en los clientes y como el conocer esto le permite adelantarse a las futuras necesidades, que no solo resuelvan de la mejor manera la necesidad del consumidor, sino que además provoque un alto grado de satisfacción, lo que conducirá al cliente a una lealtad hacia la marca.

\section{Palabras Clave:}

Creatividad, ideas, productos, clientes 


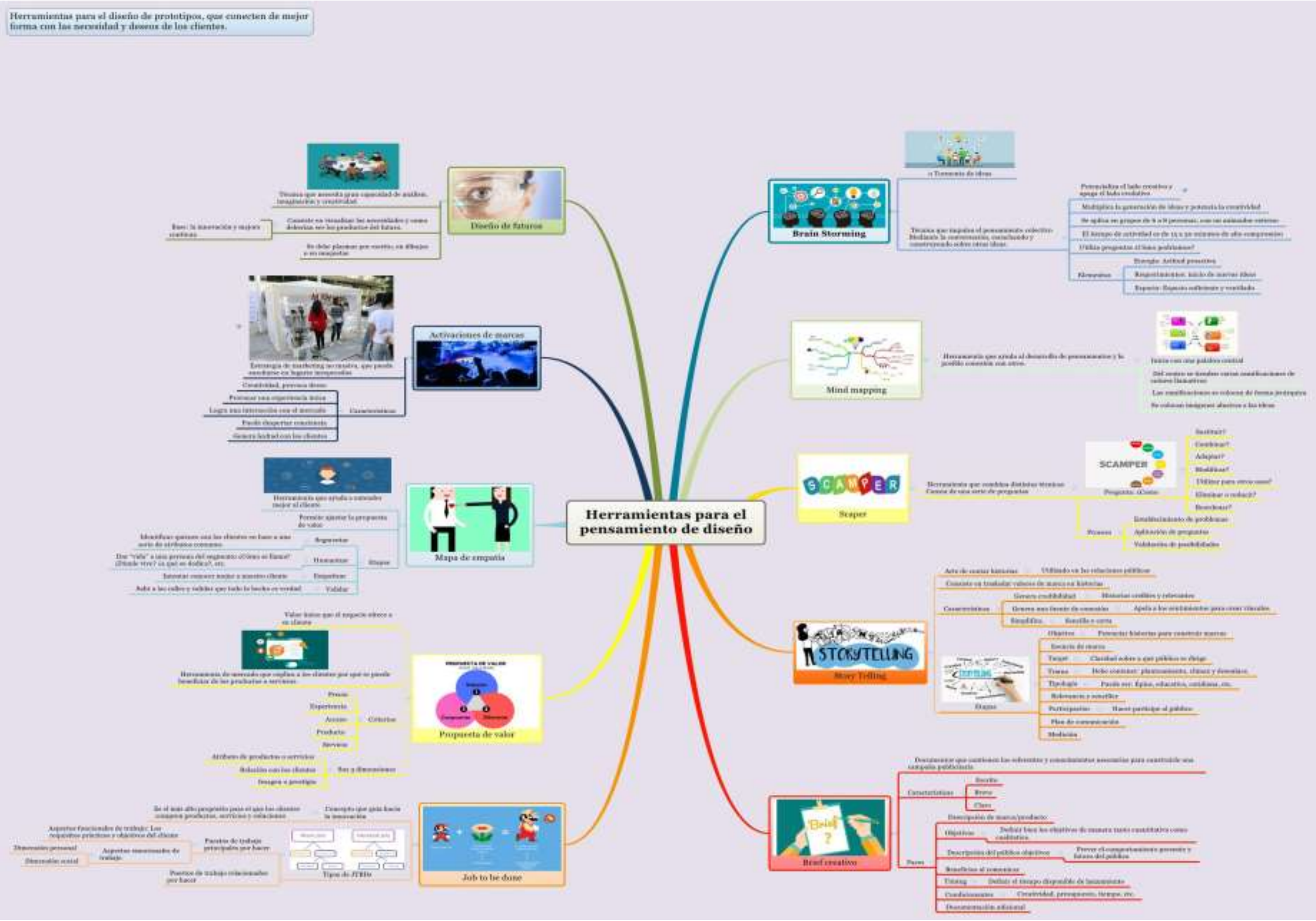




\section{Referencias}

Brainstorming, consultado en febrero 2020 en https://www.niu.edu/facdev/_pdf/guide/strategies/brainstorming.pdf

Mid map para el desarrollo de proyectos, consultada en febrero 2020 en https://ior.es/noticias/mind-map-proyectos/

James, W (2017 ) Método Scamper, cómo generar ideas, consultado en

febrero 2020 en https://www.innovacion.cr/sites/default/files/article/adjuntos/herramientas _practicas_para_innovacion_1.0_scamper_1.pdf

Zarameño, G(2017), El Storytelling como herramienta para la construcción del relato transmedia en la enseñanza de la Historia Económica y el Marketing, consultado en febrero 2020 en https://www.researchgate.net/publication/329029230_El_Storytelling_co mo_herramienta_para_la_construccion_del_relato_transmedia_en_la_ense nanza_de_la_Historia_Economica_y_el_Marketing

Robertson, C. (s/f) Briefas Creativos y Briefings, consultado en febrero de 2020 en http://fido.palermo.edu/servicios_dyc/blog/docentes/trabajos/46882_1865 98.pdf

Tecnológico de Monterrey (2013) Jobs-To-Be-Done, consultado en febrero 2020 en https://www.google.com/sea rch?rlz=1C1GCEA_esMX820MX820\&ei=iY

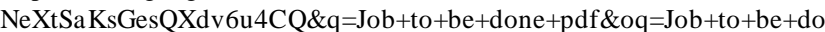
ne+pdf\&gs_l=psy-ab.3..0j0i22i3019.2902.4843..5437...0.2..0.418.1199.2$2 \mathrm{j} 1 \mathrm{j} 1 \ldots . . .0 . . .1$...gws-

wiz......0i71j0i67.qwW_OADQQ_I\&ved=0ahUKEwiUg _U2v7nAhVBT6wKHd3fCpcQ4dUDCAs\&uact=5

Mejía, C. (s/f) La propuesta de valor, consultado en febrero 2020 en http://www.planning.com.co/bd/mercadeo_eficaz/Julio2003.pdf

LN Creatividad y Tecnologia (2017) ¿Qué es Design Thinking? Pensamiento de Diseño, consultado en febrero 2020 en https://www.luisan.net/blog/diseno-grafico/que-es-design-thinking 